\title{
ORIGINAL
}

\section{BROTE DE GASTROENTERITIS POR VIRUS NORWALK EN UNA RESIDENCIA DE ANCIANOS DE GRANADA}

Diego Almagro Nievas D, Francisco Conti Cuesta, Esther Espínola García, Carolina Morcillo Ródenas, Cristina Núñez Sevilla, Juan Linares Torres y Juan Ortiz Espinosa.

Distrito Sanitario Agrupación Loja Santa Fe.

\section{RESUMEN}

Fundamento: Los brotes de gastroenteritis aguda de origen vírico son actualmente uno de los problemas de salud que más están edad. El objetivo del estudio es investigar las causas del origen y transmisión de un brote de gastroenteritis aguda por virus NorwalLike.

Método: En una residencia de ancianos con 141 residentes y 71 trabajadores expuestos, se investigó la relación entre un brote de gastroenteritis aguda y distintas variables: características personales, de lugar, fecha de inicio de los síntomas, clínica de la enfermedad y factores causales (alimentos y agua de consumo). Se realizó un es descriptivo, 2 , diseño de casos y controles con el calculo de Odds Ratio cruda y posteriormente ajustada (IC al 95\%) utilizando regresión logística.

Resultados: No se observaron diferencias significativas en las variables de características personales y de lugar. La tasa de ataque en los residentes fue del $30,1 \%$ y en trabajadores fue del $21,12 \%$. En el calculo de la Odds Ratio ajustada sólo tuvo valores de relación causal la mousse de nata (Odds Ratio ajustada=4,66; IC-95\% 18,91: $\mathrm{p}=0,031)$. Se remitieron 10 muestras de heces de enfermo para su análisis, no detectándose ninguna bacteria patógena, pero si se aisló en 3 de ellas virus Norwal-Like.

Conclusiones: El hallazgo de la mousse de nata como posible responsable del brote supone una primicia en la presencia de virus Norwalk, pero este resultado está sujeto a limitaciones, como el posible sesgo de clasificación por no recuerdo de consumo de alimentos. Aún así, supone un elemento a tener en cuenta en el control de gastroenteritis agudas por virus.

Palabras clave: Higiene de los alimentos. Contaminación ambiental. Virus Norwal-Like. Gastroenteritis aguda. Brote epidémico. Ancianos.

Correspondencia:

Diego Almagro Nievas

$\mathrm{C} / \mathrm{LaPaz}^{\circ} 2$

18320 Santa Fe (Granada)

Correo electrónico: alminero@cica.es

\section{ABSTRACT}

\section{Outbreak of Gastroenteritis Caused by Norwalk Virus at a Senior Citizen Assisted Living Facility in Granada, Spain}

Background: The outbreaks of acute gastroenteritis caused by a virus are currently one of the health problems having the greatest impact on those living in senior citizen facilities. The objective of this study is that of investigating the causes of the start and contagion of an outbreak of acute gastroenteritis caused by a Norwalk-Like virus.

Method: At a senior citizen living facility with 141 residents and 71 employees exposed, the relations between the disease in question and different independent variables: personal traits, features of location, date of onset of symptoms, clinical pattern of the disease and causal factors (food and drinking water intake). A descriptive study, a contingency table and a hypothesis ?2 test, design of cases and controls with the calculation of the unprocessed and subsequently adjusted Odds Ratio (IC 95\%) were carried out using logic regression.

Results: No significant differences were found in the personal trait and features of location variables. The attack rate among the residents was $30.1 \%$, being $21.12 \%$ among the employees. In the adjusted Odds Ratio calculation, solely the whipped cream mousse showed causal relationship values (adjusted Odds Ratio $=4.66$; IC $95 \% 1.15-18.91 ; \mathrm{p}=0.031$ ). Ten patient stool samples were sent for analysis, no disease-causing bacteria having been detected, Norwalk-Like virus however having been isolated in three samples.

Conclusions: The whipped cream mousse having been found to possibly have been responsible for the outbreak is a first involving Norwalk virus, but this result is subject to limitations, such as the possible bias of classification due to failing to recall having eaten foods. Even so, this is an element to be taken into account in the control of acute viral gastroenteritis.

Key words: Virus Norwal-Like. Gastroenteritis acute. Epidemic outbreaks. Elderly people. 


\section{INTRODUCCIÓN}

Los virus Norwalk-Like (NLV), antes conocidos como partículas virales redondas de pequeño tamaño (small round structured viruses -SRSV-), constituyen un grupo heterogéneo de virus, que pertenecen a la familia de los Caliciviridae y género Norovi$r^{1}{ }^{1}$. Son los responsables de al menos un $40 \%$ de los brotes de gastroenteritis aguda (GEA) de origen vírico en adultos en diferentes instituciones ${ }^{2,3}$. De los 348 brotes de GEA que notificaron los Centers for Disease Control and Prevention (CDC) entre enero 1996 y noviembre de 2000, el $39 \%$ fue en psiquiátricos y residencias de tercera edad, $29 \%$ en hospitales, $12 \%$ en escuelas y guarderías, $10 \%$ en cruceros de vacaciones y $9 \%$ en otros lugares ${ }^{4}$. Igualmente se han descrito diferentes vehículos de transmisión de estos virus; así tenemos diferentes tipos de alimentos (especialmente de alimentos marinos de consumo crudo), consumo de agua (contaminada por materias fecales) y por contacto directo entre las personas (contaminación fecal-oral). Esta distribución apunta a que está presente y circula por toda la comunidad, habiéndose descrito brotes en gran variedad de ámbitos y lugares como equipos de fútbol americano ${ }^{5}$, hospitales ${ }^{6}$, residencias de ancianos ${ }^{7}$, establecimientos alimen$\operatorname{tarios}^{8}$ y en la población general por contaminación hídrica ${ }^{9}$. Para los CDC la comida estaba implicada en el 39\% de los brotes, de persona a persona en un $12 \%$, agua en un $3 \%$ $\mathrm{y}$ un $18 \%$ no se pudo identificar su modo de transmisión ${ }^{2}$.

Pese a esta gran distribución espacial, la bibliografía apunta a que se produce una subnotificación por una evolución autolimitada de la enfermedad (24-48 horas) y la dificultad diagnóstica por precisar microscopía electrónica para su confirmación y la rapidez con que el virus desaparece de las heces ${ }^{3}$.

La investigación de una mayoría de los brotes encontrados en la bibliografía, se ha realizado de forma retrospectiva. En los des- critos en residencias se destaca la mayor afectación de residentes que de trabajadores $^{10}$.

La notificación urgente a la autoridad sanitaria debe servir para la pronta recogida de muestras biológicas de las personas afectadas, la identificación del posible mecanismo de transmisión con toma de muestras ambientales si fuesen necesarias, y la implantación de medidas preventivas pertinentes para evitar su propagación entre el resto de residentes sanos y empleados.

Entre los días 5 y 7 de diciembre de 2001 se produjo un brote de GEA, de inicio explosivo, en una residencia de ancianos de Granada con 141 residentes y 71 trabajadores expuestos. El estudio epidemiológico se inició el 7 de diciembre. Se da las circunstancias que durante el año 2001 también se nos notificó otro brote confirmado por laboratorio en nuestro distrito sanitario y con un mecanismo de transmisión de persona a persona en otra residencia ubicada en otra población distinta.

El objetivo del estudio es investigar las causas del origen y transmisión de un brote de gastroenteritis aguda en una residencia de la tercera edad y sus trabajadores.

\section{SUJETOS Y MÉTODOS}

La población de estudio son todos los residentes presentes en la residencia de la tercera edad y los trabajadores que estuvieron prestando sus servicios los días que duró el brote.

Para llevar a cabo la investigación epidemiológica se realizó un estudio de casos y controles. Se definió como caso en personas institucionalizadas: cualquier persona residente en el centro que hubiese presentado vómitos y/o diarrea entre los días 5 y 10 de diciembre de 2001, descartando a aquéllas que tuviesen cualquier patología de base que 
justificara la sintomatología. Como controles se tomó a los residentes sin síntomas de GEA que durante el periodo de estudio se encontraban en la residencia. Para la confirmación de caso hubiese sido deseable utilizar la técnica $\mathrm{PCR}^{4}$ pero no está disponible habitualmente en el diagnostico de rutina. En la definición de brote aplicamos los criterios de Kaplan ${ }^{11}$.

La residencia de ancianos tiene tres plantas con habitaciones individuales y dobles. En la planta baja se ubican los servicios generales. En la fecha del brote había 141 ancianos en régimen de internamiento. Dispone de una sola cocina y de tres comedores, uno situado en la planta baja y los otros dos en la planta segunda. En todos ellos, a excepción de la cafetería, el menú es preparado y servido desde la cocina central. Éste se programa con una semana de antelación. En la tabla 1 se describen los menú consumidos los dos días anteriores al comienzo de los síntomas. Los trabajadores habitualmente no toman alimentos en la residencia.

A través de encuesta epidemiológica se investigaron las variables independientes que hacían referencia a las características personales (edad, sexo), de lugar (si estaba sólo en la habitación o acompañado y su ubicación en plantas y alas), fecha de inicio de síntomas y clínica de la enfermedad (nauseas, vómitos y diarrea), así como de los factores que se consideraron que podrían estar implicados en la aparición y extensión del brote: comidas realizadas desde la cena dos días antes al inicio de síntomas y agua consumida. A los pacientes con problemas psíquicos no se les pudo encuestar de forma detallada. Las auxiliares cuidadoras fueron las que realizaron la encuesta sobre alimentación en 23 casos y 33 controles. El resto de variables fueron recogidas por dos médicos; uno el titular de la residencia y otro perteneciente al distrito.

Los trabajadores afectados fueron 15 con la misma definición de caso que en las personas ingresadas. Se tomó la decisión de no incluirlos en el estudio de casos y control por observar ya inicialmente que las categorías profesionales que están más en contacto con los enfermos (enfermeras y auxiliares de geriatría) son las que se afectaban supuestamente por contagio de forma secundaria y porque no tomaban los mismos alimentos que los residentes.

Durante los días 7 y 8 del brote se tomaron 10 muestras de heces a personas residentes que presentaban diarrea. No se investigaron muestras de heces de manipuladores de alimentos por no tener antecedentes de enfermedad. Cuatro muestras fueron enviadas para estudio de bacterias enteropatógenas y el resto para investigación de virus al Centro Nacional de Microbiología (CNM) del Instituto de Salud Carlos III, siguiendo las recomendaciones establecidas por el mismo y junto con un pequeño resumen del brote.

Tabla 1

Los menús consumidos en los dos días anteriores de inicio del brote

\begin{tabular}{|lll|}
\hline & DIA 3/12/2001 & DIA 4/12/2001 \\
\hline COMIDA & $\begin{array}{l}\text { CoMIDA } \\
\text { Rosada plancha } \\
\text { Fruta }\end{array}$ & $\begin{array}{l}\text { Lentejas } \\
\text { Sopa de verduras } \\
\text { Chuletas } \\
\text { Yogur }\end{array}$ \\
CENA & $\begin{array}{l}\text { CENA } \\
\text { Crema de puerros } \\
\text { Pollo plancha } \\
\text { Natillas }\end{array}$ & Sopa de verduras \\
& Merluza a la vasca \\
& Mousse de nata \\
\hline
\end{tabular}


El día 7 se realizó una primera inspección a la residencia por parte del coordinador veterinario, la epidemióloga del dispositivo de apoyo del distrito y la farmacéutica titular de la zona. La hipótesis inicial de la causa del brote fue el consumo de agua. El agua de consumo procede de la red de abastecimiento general de la localidad y se distribuye por todas las dependencias de la residencia, almacenándose antes de su entrada en todo el edificio en un aljibe situado en la parte superior del mismo. Según los trabajadores, el aljibe (de unos 150.000 litros) puede tardar aproximadamente 48 horas en renovar el agua y no tiene tratamiento de desinfección en ningún punto de la red interna. Se tomaron muestras de agua que fueron enviadas al laboratorio de salud pública de la Delegación Provincial de Salud de Granada para su estudio físico-químico y bacteriológico. No se pudieron recoger muestras de alimentos por no haber quedado restos; aunque en los menús que se sirvieron en días anteriores no había alimentos que la bibliografía recoge como posibles vehículos de la etiología vírica que inicialmente se sospechó ${ }^{9}$.

De los 141 residentes, 5 se excluyeron del estudio por carecer de suficiente información de interés sobre los mismos. Inicialmente se realizó un estudio descriptivo de las características personales y de lugar de los residentes (136) y afectados (41). Posteriormente se realizaron tablas de contingencia y test de hipótesis $\chi^{2}$ entre las variables de las personas enfermas y sanas y, por último, se planteó un diseño de casos y controles con el cálculo de OR cruda. Para la construcción del modelo de enfermar, se utilizó la metodología de análisis de regresión logística (con el procedimiento de hacia delante condicional) con cálculo de la OR ajustada y su IC al 95\%. La construcción de la base de datos fue con la hoja de cálculo Excel 2000 y el análisis descriptivo de los datos y el cruce de variables mediante tablas simples y análisis multivariante fue realizado con el programa estadístico SPSS/PC v9.

Tabla 2

Distribución del total de residentes y trabajadores y de casos que enfermaron según las distintas variables

\begin{tabular}{|c|c|c|c|c|c|c|c|c|}
\hline \multirow{2}{*}{ Variable } & \multicolumn{2}{|c|}{ Residentes } & \multicolumn{2}{|c|}{$\begin{array}{l}\text { Residentes } \\
\text { enfermos }\end{array}$} & \multicolumn{2}{|c|}{ Trabajadores } & \multicolumn{2}{|c|}{$\begin{array}{c}\text { Trabajadores } \\
\text { enfermos }\end{array}$} \\
\hline & Número & $\%$ & Número & $\%$ & Número & $\%$ & Número & $\%$ \\
\hline Población & 136 & 100 & 41 & 30,01 & 71 & 100 & 15 & 21,12 \\
\hline Sexo Hombre & 33 & 24,3 & 9 & 22,0 & 13 & 18,3 & 1 & 6,7 \\
\hline Mujer & 103 & 75,7 & 32 & 78,0 & 58 & 81,7 & 14 & 93,3 \\
\hline Alas Planta baja & 16 & 13,7 & 4 & 9,8 & & & & \\
\hline Ala $1 \mathrm{~A}$ & 24 & 20,5 & 8 & 19,5 & & & & \\
\hline Ala $1 \mathrm{~B}$ & 24 & 20,5 & 14 & 34,1 & & & & \\
\hline Ala 2 A & 17 & 14,5 & 3 & 7,3 & & & & \\
\hline Ala 2 B & 36 & 30,8 & 12 & 29,3 & & & & \\
\hline Perdidos & 19 & & & & & & & \\
\hline Planta Baja & 16 & 13,7 & 7 & 17,1 & & & & \\
\hline Primera & 48 & 41 & 18 & 43,9 & & & & \\
\hline Segunda & 53 & 45,3 & 16 & 39,0 & & & & \\
\hline Perdidos & 19 & & & & & & & \\
\hline Tipo de habitación & & & & & & & & \\
\hline Individual & 51 & 43,6 & 16 & 39,0 & & & & \\
\hline Doble & 66 & 56,4 & 25 & 61,0 & & & & \\
\hline Perdidos & 19 & & & & & & & \\
\hline
\end{tabular}

No coincide la planta baja ala con la planta baja. 


\section{RESULTADOS}

El resultado de la medición del cloro libre del agua de consumo fue positivo $(>0,2$ $\mathrm{ppm}$ ) en varios puntos de muestreo, excepto en una fuente de agua refrigerada que hay en la planta baja, junto a recepción.

En la tabla 2 se recoge la distribución del total de personas residentes, trabajadores y casos según las distintas variables. Las tasas de ataque especifica para las mujeres fue del $31,07 \%$ y $27,27 \%$ en los hombres.

La tasa de ataque en trabajadores fue del $21,12 \%$. Entre éstos y por categoría profesional, nos encontramos que por número de afectados fueron los auxiliares de geriatría los que se afectaron en primer lugar (9/29), secundariamente las trabajadoras de la limpieza (aunque por tasa de ataque fueron las más afectadas (3/7) y posteriormente las enfermeras (2/6). Se dio un caso en un trabajador de mantenimiento pero su mujer, auxiliar de geriatría, había enfermado dos días antes. Entre el personal de administración de la residencia no hubo notificación de caso alguno de GEA durante todo el periodo epidémico.

En la tabla 3 y figura 1, se observa la descripción de la variable edad y su distribución por grupos en residentes y casos.

La sintomatología más importante fueron vómitos $(73,9 \%)$ y diarrea $(47,8 \%)$. La duración de la enfermedad fue de 24-48 horas y no fue necesario realizar hospitalizaciones.

En la figura 2 se representa la forma de presentación de al enfermedad ende los residentes y trabajadores. En los residentes los primeros 23 casos aparecieron el día 5 de diciembre a partir de las 9 horas y los últimos 4 casos el día 7. Si se toma en consideración la fecha y hora de la toma de la cena del último día y teniendo en cuenta sólo los casos que comenzaron el día 5 y el 6 (debido a que es lo que suele durar la enfermedad por término medio y para evitar los posibles casos secundarios que pueden aparecer al tercer día), el periodo de incubación en horas se estableció entre un rango mínimo de 13 horas, máximo de 51 y una mediana de 23

Tabla 3

Distribución de la edad entre todos los residentes y los enfermos

\begin{tabular}{|cccccc|}
\hline Edad & Frecuencia & Mínimo & Máximo & Media & D.e. \\
\hline Todos & 136 & 48 & 101 & 83,21 & 8,4 \\
Enfermos & 41 & 56 & 101 & 82,98 & 9,77 \\
\hline
\end{tabular}

Figura 1

Distribución por grupos de edad en residentes y enfermos

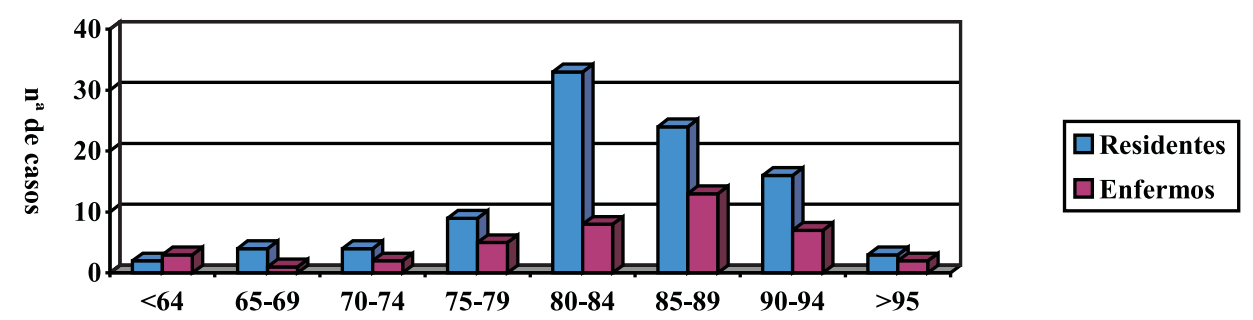


Figura 2

Curva epidémica en residentes y trabajadores

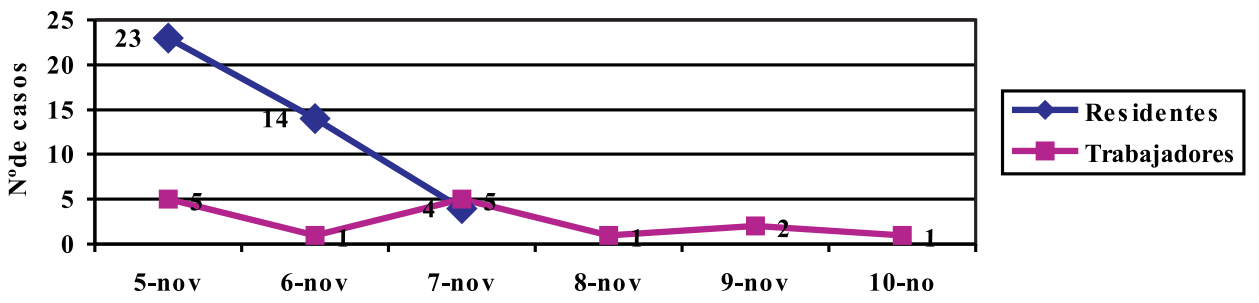

horas (media de 27 horas). En los trabajadores se presentaron casos entre los días 5 y 10 de diciembre con un mayor número de casos los días 5 y 7 ( 5 casos cada día), con un descenso en los tres días posteriores. Entre los trabajadores hubo casos en todos los días que dura el brote, lo que habla de un mecanismo de transmisión de persona a persona.

De los 136 residentes sólo de los que al final se conoció su ubicación, destaca que por alas fue en la $1^{\mathrm{a}} \mathrm{B}$ son donde más enfermos con relación a sanos presentó $(12 \%$ frente al $8,5 \%$ ) y en el resto a la inversa. No hay diferencias significativas $(p=0.067)$. En todas las plantas y por tipo de habitación, el porcentaje de enfermos es menor que el de no enfermos, sin que exista relación estadísticamente significativa.

En el análisis bivariante entre los casos y controles, la probabilidad de enfermar entre los residentes durante todo el periodo del brote, relacionada con las variables de consumo incluidas en el estudio sólo se encontró asociación estadísticamente significativa entre la aparición de la enfermedad con haber comido mousse de nata durante la cena del día $4(\mathrm{ORc}=4,67$; IC-95\%=1,03$24,54 ; \mathrm{p}=0,023)$ y pollo a la plancha en la cena del día $3(\mathrm{ORc}=4,17$; IC-95\%=0,82$21,73 ; \mathrm{p}=0,039)$, aunque este último el intervalo de la OR comprende la unidad. El análisis multivariante mediante regresión logística muestra que la probabilidad de enfermar durante la fase explosiva, ajustada por el resto de variables incluidas en el modelo, es de
4,66 veces más si comieron mousse de nata en la cena del día 4 de noviembre que si no lo tomaron, controlando por el resto de variables independientes consideradas (OR ajustada $=4,66$; IC-95\% 1,15-18,91; p=0,031) (tabla 4). El agua consumida por dos residentes que enfermaron fue en todo momento embotellada y con la peculiaridad de que uno comenzó el mismo día de inicio del brote y otro a las 72 horas. El consumo de agua de la fuente que tuvo resultados de cloro residual negativo entre los residentes y trabajadores no es habitual, sobretodo en invierno.

El hecho de que el residente haya compartido habitación no se relaciona con una mayor probabilidad de aparición de nuevos casos, como podría esperarse ante una transmisión de persona a persona.

Tabla 4

Riesgo de enfermar en los residentes por consumo de alimentos. Análisis multivariante

\begin{tabular}{|cccc|}
\hline Variables & ORa & $I C 95 \%$ & $p$ \\
\hline crema (1) & 0,10 & $0.01-1,18$ & 0,068 \\
pollo (1) & 4,00 & $0,47-33,05$ & 0,200 \\
natillas (1) & 0,80 & $0,05-11,24$ & 0,873 \\
lentejas (1) & 0,82 & $0,10-6,55$ & 0,856 \\
sopaver (1) & 1,29 & $0,15-10,84$ & 0,815 \\
chuletas (1) & 0,44 & $0,04-4,18$ & 0,480 \\
yogur (1) & 2,05 & $0,28-14,72$ & 0,472 \\
sopaver (1) & 9,16 & $0,74-113,73$ & 0,085 \\
merluza (1) & 0,81 & $0,10-6,12$ & 0,844 \\
mousse (1) & 4,66 & $1,15-18,91$ & 0,031 \\
agua (1) & 0,00 & $0.00-1,7 \mathrm{E}+31$ & 0,828 \\
\hline
\end{tabular}

Rev Esp Salud Pública 2003, Vol. 77, N. ${ }^{\circ} 2$ 
En los análisis realizados por el laboratorio del hospital de referencia no se aisló ningún germen patógeno en las muestras de heces de enfermos. El CNM identificó, mediante microscopía electrónica, Calicivirus (NLV) en 3 muestras de heces.

El análisis de agua procedente de la red de abastecimiento general mostró un buen estado de cloración con valores de cloro residual superiores a $0,2 \mathrm{mg} / \mathrm{l}$ en los puntos muestreados. Las determinaciones organolépticas, microbiológicas y físico-químicas fueron normales. No se dispone de resultados de análisis de alimentos y agua consumidos los 2 días anteriores al inicio brote.

\section{DISCUSIÓN}

Desde el punto de vista metodológico el hecho de no incluir a 5 residentes por falta de información pensamos que no puede cambiar los resultados, pues la variabilidad que puedan representar dichas pérdidas no puede ser muy diferente del resto. Igualmente las 19 pérdidas en variables de ubicación de la población residente total y que están comprendidas entre los que no enfermaron, pensamos que no cambian el resultado porque en el estudio casos control no da resultados significativos. La selección de casos y controles es homogénea en cuanto a su distribución por toda la residencia, por lo que es difícil pensar en un sesgo de selección.

El sesgo de clasificación que se puede presentar por el tipo de población encuestada puede ser evidente y máxime cuando se tardó dos y tres días en realizar la misma. Las encuestas sobre alimentación son las que podrían dar este sesgo. El resto de variables se han obtenido de los registros médico y de enfermería. Las encuestas sobre alimentación se han realizado antes de confirmar la etiología viral y no había alimentos sospechosos que pudieran influir en un mayor énfasis en obtener la respuesta de los residentes. También es cierto que este tipo de sesgo da una clasificación errónea no diferencial que tiende hacia el valor nulo.

En la distribución espacial de los enfermos en la residencia observamos como hay diferencias entre las distintas alas, plantas y tipo de habitación, pero estas diferencias no fueron estadísticamente significativas, lo que apoya que la exposición fue de una fuente común y no de persona a persona.

Los brotes por virus NVL, se han asociado a una exposición a fuente común por ingesta de diversos alimentos de consumo crudo, entre los cuales están las verduras, frutas frescas y mariscos. No hemos encontrado descrito en la bibliografía ningún brote por Calicivirus atribuido al consumo de mousse de nata, aunque sí por virus de la hepatitis A en mousse de frambuesa ${ }^{12}$.

La curva epidémica de los residentes enfermos, con un ascenso rápido del número de casos durante el primer día y un descenso progresivo en los dos días siguientes, corresponde a un brote explosivo provocado por la exposición a una fuente común y con un corto periodo de incubación. Al tercer día sí puede haber transmisión desde un compañero o un trabajador enfermo.

La curva epidémica entre los trabajadores corresponde a una transmisión inicial de 5 y después se va alargando a lo largo de los días, como corresponde a un mecanismo de transmisión de persona a persona. Los trabajadores manifestaron no haber consumido alimentos en la residencia en los días precedentes al brote. La aparición en el resto de trabajadores hace compatible la hipótesis de su contagio a partir del contacto con enfermos, sin que pueda establecerse con exactitud el momento. Las 5 auxiliares de geriatría que manifestaron comenzar con los síntomas el mismo día que el mayor número de casos, declararon que no tomaron el alimento sospechoso (mousse de nata) y, efectivamente, dos tienen turno de mañana, dos de tarde (éstas sí podían haberlo consumido) y 
una tenía descanso. El día 5, cuando se produjo el mayor número de residentes enfermos, todas estaban trabajando (3 de turno de mañana y 2 de tarde). La exposición máxima al virus podría disminuir el periodo de incubación, de hecho se han descrito periodos mínimos de hasta 3 horas ${ }^{7}$. La exposición a partículas de aerosoles procedentes de vómitos de enfermos, también recogida como vía de transmisión ${ }^{13}$, podría explicar otra vía de entrada para las auxiliares y enfermeras, y tal vez la única para las limpiadoras que enfermaron. La dosis infectante para este virus es muy baja, por lo que pronto hay una gran probabilidad de coger la enfermedad por manipulación de fómites de los enfermos, transmitirse de persona a persona y por contaminación medioambiental ${ }^{14}$. Esto puede explicar en definitiva que sea el personal de enfermería y de limpieza los que más enfermaron entre los trabajadores.

Un periodo de incubación medio de 27 horas en los residentes es compatible con la hipótesis de que el brote tuvo su origen tras una exposición común durante la comida del día 4 de noviembre, apareciendo el primer caso 10 horas después y con una agrupación temporal de casos bien definida en las $19 \mathrm{y}$ 25 horas posteriores, prolongándose el brote para los residentes durante 2 días más hasta finalizar de manera espontánea. Todo ello coincide con la bibliografía consultada 9 .

El cuadro clínico que presentaron los enfermos, la duración del brote y la elevada tasa de ataque secundario, son compatibles con la presentación característica de los brotes provocados por Calicivirus. La identificación por el laboratorio del CNM de virus de NVL en muestras biológicas de 3 residentes enfermos hace probable su implicación como agente causal del brote epidémico. No hay diferencias significativas de las edades, lo que también coincide con otros estudios consultados $^{6,15}$.

En la literatura encontramos tasas de ataque de un $50 \%$ y que el $80 \%$ de los presentes se ha comprobado que habían tenido contacto con el virus. Si consideramos que la causa del brote ha sido el consumo de la mousse de nata, el porcentaje de los que lo consumieron según el estudio de casos y controles, fue del $50 \%$. También coincide la tasa de ataque en trabajadores, que siempre es más baja que en residentes $^{16}$.

En la tabla 4 la sopa de verduras tiene indicadores cercanos a la significación estadística, aunque tanto por el intervalo de confianza, como por la forma en que se suele servir (caliente), no parece posible que sea un alimento implicado en el brote.

Las características sanitarias encontradas en el agua de la red general y las diferencias en la distribución espacial y temporal de casos hacen que sea poco probable la implicación del agua de la red como vehículo de transmisión de la enfermedad. De todas formas el virus sobrevive a altas concentraciones de cloro libre y la presencia de coliformes en agua se ha tomado como referencia de contaminación por virus ${ }^{1}$.

En este brote se cumplen los criterios Kaplan et al11 (coprocultivos negativos a bacterias enteropatógenas, vómitos por encima del $50 \%$, duración de la enfermedad de 12 a 60 horas y período de incubación de 24 a 48 horas).

La vigilancia epidemiológica de GEA en residencias de ancianos mediante sistemas rápidos de identificación y registro, el entrenamiento y la educación sanitaria del personal que atiende a esta población, así como la intervención de profesionales expertos que asegure un control rápido de estos brotes, serían medidas a adoptar para su prevención y control efectivo.

Podemos decir que se trató de un cuadro de GEA por etiología viral, más concretamente por el virus NLV, dado en una residencia de ancianos y en trabajadores y que la exposición fue a una fuente común, pudien- 
do ser el consumo de mousse de nata. Es posible que estudios posteriores puedan refrendar o modificar esta posible causa al aumentar la notificación rápida y posibilitar la determinación del virus en alimentos en las primeras 48 horas de inicio de síntomas a través de la microscopía electrónica

\section{AGRADECIMIENTOS}

A Sandra A Pinzón Pulido por su colaboración inestimada. A los profesionales la residencia de ancianos por su total predisposición para el control del brote y la recogida de información. A los técnicos de Laboratorio Nacional del Microbiología del ICIII por su preocupación y celeridad en la comunicación de los resultados.

\section{BIBLIOGRAFÍA}

1. Virus Taxonomy. Reports of International Committee on Taxonomy of Viruses. http://www.ncbi. nih.gov/ICTVdb/Ictv/fr-fst-h.htm [disponible el 9 agosto 2002].

2. Blacklow NR. Greenberg HB. Viral gastroenteritis. N Engl J Med 1991;325:252-64.

3. García Valviberas R, Hernández Pezzi, Tello O, Herrera I, Vivo A, De la Loma A. Brotes de gastroenteritis aguda por calicivirus Norwalk-like en España. Madrid: Reunión Científica de la SEE; 2000 .

4. Norwalk-Like Viruses. Public Health Consequences and Outbreak Management. MMWR 2001; 50:9.

5. Becker KM, Moe CL, Southwick KL, MacCormack JN. Transmission of Norwalk Virus during a Football Game. N Engl J Med 2000;343:12237.

6. Russo PL, Spelman DW, Harrington GA, Jenney AW, Guneseker IC, Wrigth PJ, Doultree JC, Marshall JA. Hospital outbreak of Norwalk-like virus Infect control Hosp Epidemiol 1997; 18: 576-9.
7. Marx A, Shay DK, Noel JS, Brage C, Bresee JS Lipsky S, Moroe SS, Ando T, Humphrey CD, Alexander ER, Glass RI. An outbreak of acute gastroenteritis in a geriatric long-term-care facility: combined application of epidemiological and molecular diagnostic methods. Infect Control Hosp Epidemiol 1999; 20:306-11.

8. Godoy P, Torres J, Guix S, Prat A, Alseda M, Domínguez A, Bosch A, Salleras L. Toxiinfección alimentaria por ostras causada por virus norwalklike. Med Clín (Barc) 2000; 114; 765-8.

9. Chover Lara JL, Pastor Vicente S, Roig Sena FJ, Roselló Pérez M, Salvo Samanes C, Castellanos Martínez I. Brote de Gastroenteritis asociado al consumo de agua, posiblemente producido por virus de Norwalk o semejantes. Rev Esp Salud Publica 1995; 69: 343-54.

10. Rodríguez EM, Parrot C, Rolka H, Monroe SS, Dwyer DM. An outbreak of viral gastroenteritis in a nursing home importame of excluding ill employees. Infect Control Hosp Epidemiol 1996; 17:587-92.

11. Kapplan J, Fedman R, Douglas S, Cambell D, Lookabaugh C, Gary W. The frequency of a like pattern of illness in outbreaks of acute gastroenteritis. Am J Public Health 1982; 72:1329-32.

12. Reid TMS, Robinson HG. Frozen raspberries and hepatitis A Epidemiol Infect 1987; 98: 109-12.

13. Chadwick PR, MaCann R. Transmission of a small round structured virus by vomiting during a hospital outbreak gastroenteritis. J Hosp Infect 1994:26:251-59.

14. Le Baron CW, Furutan NP, Lew JF, Allen JR, Gouvea V, Moe C, Monroe SS. Viral Agents of Gastroenteritis Public Health Importance and Outbreak Management : MMWR 1990; 39:1-24.

15. Mayoral Cortes JM, Mateo Ramos A, Pons Sánchez $\mathrm{M}^{\mathrm{a}} \mathrm{C}$, Herrera Calvez, Gutiérrez Ávila G, Vivo Rodríguez A, García Fernández M, Herrera Guilbert D, Martínez Navarro F. Brote de gastroenteritis en una residencia de ancianos de Albacete. Rev Salud Pública 2000; 74: 561-572.

16. García Fernández M, Mayoral Cortes JM. Brote de gastroenteritis en residencia de ancianos de Sevilla. Madrid: XVIII Congreso de la Sociedad Española de Epidemiología; 2000. 